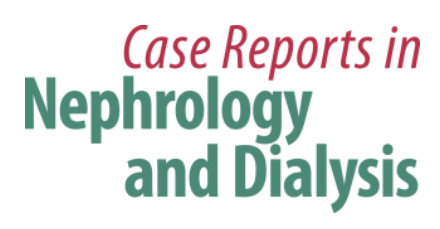

\title{
A Case Report on Allergic Rash Caused by Icodextrin
}

\author{
Şimal Köksal Cevher Nihal Ozkayar Fatih Dede \\ Nephrology Department, Ankara Numune Education and Research Hospital, \\ Ankara, Turkey
}

\section{Key Words}

Icodextrin · Peritoneal dialysis · Icodextrin hypersensitivity $\cdot$ Skin rash

\begin{abstract}
Icodextrin may be used as an alternative to glucose as the osmotic agent in peritoneal dialysis with ultrafiltration failure. In general, icodextrin is known to be safe and well tolerated, but it can also cause hypersensitivity reactions such as skin rashes. Allergic rashes are generally defined as erythematous, itchy and maculopapular, visible over the trunk and the extremities. When a rash occurs, it generally develops early in therapy, is self-limited, and resolves without sequelae after the discontinuation of icodextrin. Although the safety and efficacy of icodextrin peritoneal dialysis solution is well documented, clinicians should be aware of the possibility of severe adverse cutaneous reactions to it. We report the case of a 23-year-old female who developed a skin rash following the use of icodextrin.
\end{abstract}

(C) 2014 S. Karger AG, Basel

\section{Introduction}

Peritoneal dialysis is a type of renal replacement treatment used for end-stage renal disease. In peritoneal dialysis, glucose is used as an osmotic agent in standard peritoneal dialysis solutions, but peritoneal dialysis solutions containing icodextrin are chosen due to their high osmotic effect, particularly in patients with insufficient ultrafiltration $[1,2]$. Icodextrin is a glucose polymer derived from starch that can be metabolized into malt sugar [3]. In intraperitoneal administration, icodextrin is less absorbent than glucose. Icodextrin, due to its content, does not result in hyperglycemia and hyperinsulinemia, which are caused by glucose-containing solutions. Solutions with icodextrin are known to mostly be well tolerated by patients $[1,3]$. 


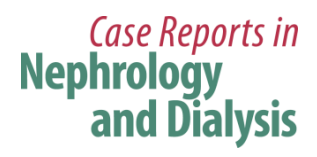

\begin{tabular}{l|l}
\hline Case Rep Nephrol Dial 2015;5:26-29 \\
\hline DOI: 10.1159/000368187 & $\begin{array}{l}\text { ○ 2014 S. Karger AG, Basel } \\
\text { www.karger.com/cnd }\end{array}$ \\
\hline
\end{tabular}

KöksalCevher et al.: A Case Report on Allergic Rash Caused by Icodextrin

The development of a rash following the use of icodextrin is very rare and defined as a case report in the literature. Our objective was to present a 23 -year-old female patient who developed a skin rash following the use of icodextrin.

\section{Case Report}

A 23-year-old female patient, who had undergone continuous ambulatory peritoneal dialysis ( 4 exchanges a day) for 1 year for end-stage renal disease, presented at our clinic complaining about stomachache, nausea, vomiting and cloudy dialysate fluid. A physical examination of the patient revealed the following: blood pressure $130 / 80 \mathrm{~mm} \mathrm{Hg}$, temperature $37.8^{\circ} \mathrm{C}$, and pulse $78 / \mathrm{min}$. An examination of other systems gave normal results except for the presence of abdominal sensitivity. The laboratory analyses of the patient provided the following results: urea $110 \mathrm{mg} / \mathrm{dl}$, creatinine $10.8 \mathrm{mg} / \mathrm{dl}$, Na $137 \mathrm{mmol} / \mathrm{l}, \mathrm{K} 4.2 \mathrm{mmol} / \mathrm{l}$, white blood cells $10,200 / \mathrm{mm}^{3}$ (85\% PMNL, $10 \%$ lymphocyte, $0.2 \%$ eosinophil); C-reactive protein $8.4 \mathrm{mg} / \mathrm{l}$, and erythrocyte sedimentation rate $76 \mathrm{~mm} / \mathrm{h}$. The white blood cell count in peritoneal fluid was $2,700 / \mathrm{mm}^{3}$, and the patient was hospitalized in our clinic and diagnosed with peritonitis. After taking peritoneal fluid cultures, intraperitoneal $1 \times 1 \mathrm{~g}$ of ceftazidime and $1 \times 1 \mathrm{~g}$ of vancomycin were empirically initiated to be administered every $96 \mathrm{~h}$ for peritonitis therapy. The $2.27 \%$ glucose solution, used for the night exchange, was replaced with icodextrin because ultrafiltration was insufficient on peritoneal dialysis assessment on day 4 of her hospitalization. The patient began to suffer from itching the next day after the use of icodextrin. The physical examination revealed redness and a rash, particularly on the neck and the upper extremities. The patient did not have a previous history of a known allergic reaction or a drug allergy; thus, the dermatology department was consulted. Because the patient had an allergic reaction, $20 \mathrm{mg}$ of methylprednisolone and 1 ampule $(45.5 \mathrm{mg}$ ) of pheniramine were administrated intravenously. This therapy did not resolve the symptoms; moreover, erythematous maculopapular lesions spread over her body and the lower extremities (fig. 1). In addition to an ongoing intravenous steroid therapy of the patient, pomade with steroids was prescribed, but the rash did not resolve despite the application of the pomade. The patient had a normal hemogram eosinophil value $\left(0.2 \%, 20 \times 10^{3} / \mu \mathrm{l}\right)$ at her hospitalization, but the eosinophil value gradually increased to $1,000 \times 10^{3} / \mu \mathrm{l}(13.4 \%)$ during her follow-up. The icodextrin therapy was interrupted after the patient had expressed an increase of her itching following the use of icodextrin. The rash and the redness began to resolve 2 days after icodextrin had been ceased, and the entire rash disappeared within 1 week. Her whole blood count showed that eosinophil dropped back to $400 \times 10^{3} / \mu \mathrm{l}(5.1 \%)$. Peritonitis regressed, and the peritoneal fluid count revealed that white blood cell count was $10 / \mathrm{mm}^{3}$. Ceftazidime and vancomycin therapy was completed in 14 days and the patient was discharged.

\section{Discussion}

Icodextrin is used as an alternative to peritoneal dialysis solutions with glucose. Icodextrin is a glucose polymer with its molecular weight being $16,600 \mathrm{Da}$, and it metabolizes into glucose from malt sugar [4]. Icodextrin provides a continuous and longer osmotic gradient because it is absorbed through the peritoneal cavity more slowly than standard peritoneal dialysis solutions $[5,6]$. Icodextrin is often preferred to increase ultrafiltration. It has clinical benefits such as improvement of blood sugar control in diabetic patients, 
improvement of lipid profiles, and enhanced phosphate removal as compared to glucosecontaining peritoneal dialysis solutions.

Icodextrin is very safe apart from possible side effects related to the skin, which is reported to be very rare. A study by Goldsmith et al. [7], which included a total of 102 patients, and 80 patients receiving icodextrin for a minimum of 6 months, reported that the development rate of skin reactions was $15 \%$. The biopsy of skin rashes showed that they appear in nonspecific inflammatory variances. Skin rashes of patients healed hours and/or weeks after the discontinuation of icodextrin. Wilkie et al. [2] reported 3 patients with limited rashes on the hands, arms and body, and Lam-Po-Tang et al. [8] reported a patient who developed severe exfoliative dermatitis 10 days after icodextrin had been initiated. In a randomized, double-blind multicenter study by Finkelstein et al. [9], maculopapular rashes were significantly higher in the icodextrin group compared to the $4.25 \%$ dextrose solution.

There is no known icodextrin epitope responsible for allergic reactions. Its construction resembles the dextran which is also used as a plasma dilator and anticoagulant and can lead to allergic reactions including anaphylaxis [10]. The only constructional difference between icodextrin and dextran are the polymer bonds between $\alpha-1,4$ and $\alpha-1,6$, respectively. $50 \%$ of the patients who receive a prolonged infusion of dextran develop rashes [11]. Recent studies have confirmed the immunogenicity of dextran and the formation of immunocomplexes with skin localization despite a lack of identification of the epitope for the dextran allergic reaction [12]. Recently, it has been noted that chronic exposure to dextran results in deposits on the skin and the peripheral nerves, which can lead to persistent rashes $[6,13]$.

Icodextin-related skin rashes usually occur on the palms and soles, but it can also develop on the body and the extremities (as in our case) $[2,14]$. The rash may be accompanied by flaking of the skin. Icodextrine-related allergic rashes usually occur during the early period of icodextrin therapy, are self-limited and heal without leaving sequelae after the icodextrin is ceased [5]. Our patient also developed an allergic reaction that caused erythematous maculopapular rashes on the skin 1 day after the use of icodextrin; it improved 1 week after icodextrin had been stopped. In general, icodextrin is known to be safe and well tolerated, but it should be noted that it can cause hypersensitivity reactions.

\section{References}

$\checkmark 1$ Mistry CD, Gokal R, Peers E: A randomized multicenter clinical trial comparing isosmolar icodextrin with hyperosmolar glucose solutions in CAPD. MIDAS Study Group. Multicenter Investigation of Icodextrin in Ambulatory Peritoneal Dialysis. Kidney Int 1994;46:496-503.

-2 Wilkie ME, Plant MJ, Edwards L, Brown CB: Icodextrin 7.5\% dialysate solution (glucose polymer) in patients with ultrafiltration failure: extension of CAPD technique survival. Peritoneal Dial Int 1997;17:84-86.

-3 Mistry CD, Gokal R: The use of glucose polymer (icodextrin) in peritoneal dialysis: an overview. Perit Dial Int 1994;14(suppl 3):S158-S161.

4 Alsop RM: History, chemical, and pharmaceutical development of icodextrin. Peritoneal Dial Int 1994;14(suppl 2):S5-S12.

5 Moberly JB, Mujais S, Gehr T, Hamburger R, Sprague S, Kucharski A, Reynolds R, Ogrinc F, Martis L, Wolfson M: Pharmacokinetics of icodextrin in peritoneal dialysis patients. Kidney Int Suppl 2002;81:S23-S33.

6 Garcia-Lopez E, Lindholm B: Icodextrin metabolites in peritoneal dialysis. Perit Dial Int 2009;29:370-376.

7 Goldsmith D, Jayawardene S, Sabharwal N, Cooney K: Allergic reactions to the polymeric glucose-based peritoneal dialysis fluid icodextrin in patients with renal failure. Lancet 2000;355:897.

-8 Lam-Po-Tang MKL, Bending MR, Kwan JTC: Icodextrin hypersensitivity in a CAPD patient. Peritoneal Dial Int 1997;17:82-84.

-9 Finkelstein F, Healy H, Abu-Alfa A, et al: Superiority of icodextrin compared with $4.25 \%$ dextrose for peritoneal ultrafiltration. J Am Soc Nephrol 2005;16:546-554.

10 Ring J: Anaphylactoid reactions to plasma substitutes. Int Anesthesiol Clin 1985;23:67-95.

11 Metze D, Reimann S, Szepfalusi Z, Bohle B, Kraft D, Luger TA: Persistent pruritis after hydroxyethyl starch infusion therapy: a result of long-term storage in cutaneous nerves. Br J Dermatol 1997;136:553-559. 
12 Valance A, Lebrun-Vignes B, Descamps V, Queffeulou G, Crickx B: Icodextrin cutaneous hypersensitivity: report of 3 psoriasiform cases. Arch Dermatol 2001;137:309-310.

13 Gall H, Schultz KD, Boehacke WH, Kaufmann R: Clinical and pathological aspects of hydroxyethyl starchinduced pruritis: evaluation of 96 cases. Dermatology 1996;192:222-226.

$\checkmark 14$ Fletcher S, Stables GA, Turney JH: Icodextrin allergy in a peritoneal dialysis patient. Nephrol Dial Transplant 1998;13:2656-2658.

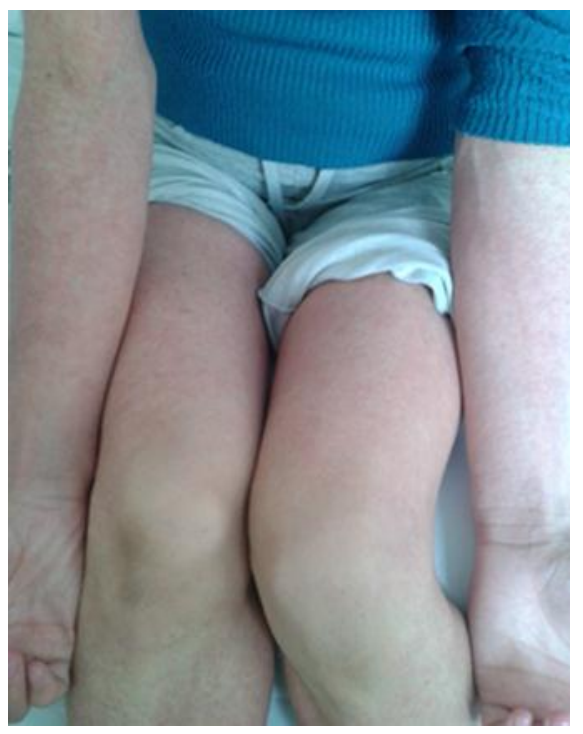

Fig. 1. Erythematous and maculopapular rashes on the upper and lower extremities. 